\title{
De elemento a cidadão: transformações no cotidiano do trabalho do policial militar
}

\author{
Fernanda Haikal Moreira, Francini Lube Guizardi, Joana Oliveira de \\ Brito Rodrigues, Rafael da Silveira Gomes, Raphaella Fagundes Daros, \\ Ricardo Bodart de Andrade, Thiago Drumond Moraes ${ }^{10}$
}

\begin{abstract}
A Polícia Militar do Espírito Santo vem passando por transformações dentre as quais se encontram a criação da Polícia Interativa e a inserção de Programas de Qualidade Total na prestação de serviços à comunidade. Essas mudanças produzem efeitos na vida do trabalhador da Polícia Militar e precisam ser vistas em conjunto com a atual situação sócio-econômica e política do país e do Estado. Na tentativa de apreender os efeitos dessas transformações na saúde do policial, realizamos um trabalho de pesquisa/intervenção junto a trabalhadores de uma determinada Companhia do $1^{\circ}$ Batalhão da Polícia Militar do Espírito Santo. A partir dos dados obtidos pudemos observar que o trabalho policial caracteriza-se pela extensão da atividade profissional a todos os âmbitos da vida do trabalhador, atravessando-a não apenas com uma determinada identificação institucional, mas também com os conflitos e contradições que demarcam a função desses trabalhadores, ocasionando um grande sofrimento mental. Sofrimento mental que é agravado pela ausência de espaços para sua análise coletiva na instituição militar.

Palavras-chave: psicologia social, polícia militar, saúde do trabalhador
\end{abstract}

$\mathrm{N}$

os últimos anos, a atuação da Polícia Militar vem sendo freqüentemente veiculada pela mídia, ultrapassando as fronteiras dos periódicos e tablóides sensacionalistas da imprensa escrita e invadindo os programas de televisão, não menos sensacionalistas. Nunca essa instituição ocupou tamanho espaço nos meios de comunicação; programas como "Aqui e Agora" (SBT), "Na Rota do Crime" (da extinta Manchete) e outros de mesma filosofia, consagraram-se mostrando diversas ações policiais e os colocando no lugar de heróis. Vimos jornais noturnos como o "Jornal Nacional" (Globo), "Jornal da Band" (Bandeirantes), "Jornal da Manchete" (da extinta Manchete) mostrarem episódios como os da Favela Naval e Cidade de Deus, colocando o policial no lugar de vilão; ou, mais recentemente, mencionando as péssimas condições de trabalho e o estresse advindo de sua atividade, colocando-os no lugar de vítimas. Não nos cabe julgar se são heróis, vilões ou vítimas. Mas considerá-los como trabalhadores situados em uma organização do trabalho que produz relações particulares, relações estas que engendram várias maneiras de estar nesse cotidiano laboral, diversos lugares a serem ocupados. E é sobre estas maneiras de estar que nossos olhares convergem.

A instituição policial, tal como se apresenta na contemporaneidade, remonta-nos ao Estado Moderno Francês no final do século XVII. Como aponta Tavares dos Santos (1997), a formação do Estado Moderno ocorreu mediante a produção de uma nova forma de poder "que combinava diversas tecnologias e práticas de poder totalizantes (...) e tecnologias de poder globalizantes" (p. 156), em meio as quais se encontra a Polícia. Surgiram, assim, vários modelos de instituição policial sendo que, dentre esses, destacaram-se os modelos francês e inglês, que serviram de referencial para as polícias de todo o mundo.

No modelo francês, a polícia surge como instituição centralizada, agente legítimo da violência física do Estado e que possui, dentre outras, a função de manter a ordem social interna. O modelo inglês é uma outra importante influência na formação da polícia brasileira

${ }^{10}$ Alunos do curso de psicologia da Universidade Federal do Espírito Santo. Supervisoras: Prof. Maria das Graças B. Moulin e Prof. Maristela Dalbello Araújo. 
e na forma em que ela hoje se apresenta. Este modelo era baseado na relação entre os policiais e a sociedade, como uma espécie de polícia comunitária, que buscava legitimar sua ação social.

Poderíamos dizer que até hoje a organização policial depende da combinação desses dois modelos, o sistema francês estatal e centralizado e o sistema inglês comunitário, aliando o exercício da coerção física legal com a busca da legitimação social (Tavares dos Santos, 1997, p. 160).

Essas influências misturaram-se no processo de democratização do País, remontando a uma realidade institucional que comporta, em suas características e contradições, as disparidades desses dois modelos. Segundo Paixão e Beato (1997), o processo democrático exige a institucionalização da violência - ainda que em tese este recurso deva ser disponibilizado apenas em último caso - a fim de que se afirme a ordem e o "consenso da maioria". Assim, o Estado retém em suas "instituições de controle social o monopólio do uso legítimo dos meios de violência" (Paixão \& Beato, 1997, p. 235). Asseguraria, dessa forma, uma determinada compreensão de cidadania afirmada na garantia do respeito às leis comuns e no respeito aos direitos e liberdades civis, paradoxalmente ameaçados pelas próprias organizações estatais.

Não é necessário explicitar a inserção da Polícia Militar como um desses instrumentos de controle social. Especialmente num país como o Brasil, ainda em afirmação e construção de seu processo democrático, e cuja história recente remete a uma longa ditadura militar, caracterizada e recordada pela violência da mencionada instituição. Assim,

...o problema social da polícia na ordem social democrática é garantir o consenso moral - seja fazendo o crime não compensar pela detenção rápida e certeira do criminoso, seja comunicando à periferia social as regras públicas de comportamento da sociedade democrática -, (...) Por outro lado, a polícia é objeto a ser contido, dado o potencial de ameaça ao pleno exercício, pelo cidadão, de suas liberdades negativas, representado pelo uso arbitrário de poder pelos agentes de estado no combate ao crime (Paixão \& Beato, 1997, p. 236).

No entanto, apesar de aparentar ser bem delimitada, a função social da Polícia Militar muitas vezes torna-se bastante contraditória em seu exercício concreto. É o que apontam Paixão e Beato (1997), ao salientarem a demanda existente por "justiça a qualquer preço", independentemente das categorias e canais legais de resolução de conflitos. Nesse sentido, verifica-se freqüentemente a aprovação de ações arbitrárias e mesmo violentas da polícia por parte da opinião pública. Deste modo, o trabalho policial defronta-se usualmente com uma clara contradição. Se, por um lado, podemos verificar o crescimento da fiscalização da sua atuação pelas instituições democráticas, por outro, temos demandas por parte da sociedade civil de uma atuação arbitrária e muitas vezes violenta para que se faça "justiça".

Essa peculiaridade pode tornar-se um pouco mais compreensível quando retomamos o processo histórico de nosso país. De acordo com Cardia (1997), a transição da ditadura para a "democracia" ocorreu de forma branda, prolongada, e não com uma revolução. Nesse meio tempo, houve espaço para que ocorressem mudanças em nossa sociedade, que a reestruturaram e possibilitaram uma nova forma de governo: "a democracia". No entanto, a imagem social da polícia não atravessou o mesmo caminho, já que com a difícil situação econômica e política do país, a violência e arbitrariedade continuaram a existir. Segundo Cardia (1997), com a classe média e alta, a polícia conseguiu construir uma outra relação que não a de "polícia opressora", mas com a classe trabalhadora, essa mudança ainda não se efetivou. E é interessante constatarmos que a maior parte dos trabalhadores da polícia militar provêm dessa classe, que ainda perpetua o pensamento social de uma "polícia para oprimir e matar". Isso reporta-nos a dois fatos importantes: primeiro que, realmente, ainda é presente a polícia que oprime e mata e, segundo, que a atuação repressiva da polícia se dá sobremaneira 
nas classes menos favorecidas da sociedade.

Somado a isso, como apontam Barbosa et al. (1998), essa ambigüidade da atuação da polícia militar resulta da forma com que foi sentida pelos componentes da corporação a mudança de regime político. Os autores falam sobre essa transição usando a seguinte analogia: um dia esses soldados formados num contexto de inquestionabilidade das ações governamentais foram para casa após uma jornada normal de trabalho como os homens "Hobbesianos", que sempre foram. No dia seguinte, tiveram que retornar aos quartéis como perfeitos iluministas; pregando e respeitando a liberdade do cidadão. Liberdade que até o dia anterior houvera sido o dever de não se opor ao governo.

Essa discussão aponta que a Instituição Policial possui um lugar social ainda em construção e, especialmente por isto, o trabalho a ela vinculado conforma-se mediante uma série de singularidades que o diferenciam de forma enfática das demais categorias profissionais. Como exemplo significativo podemos citar a organização do trabalho que a caracteriza. Na corporação militar o trabalho é estruturado a partir do militarismo, ou seja, é fundado em uma rígida disciplina e uma marcante hierarquia, as quais remontam, no Brasil, ao Império, e são caracterizadas por rituais (continência, marchas, fardas etc.) e punições (prisões) que em nada nos lembram os modernos modos de produção capitalista. Ao mesmo tempo, a Polícia Militar hoje encontra-se num esforço sistemático de implementação de técnicas e estratégias modernas de gerenciamento administrativo, por meio das quais se pretende reformular sua inserção social, tornando-a não mais um órgão estatal repressor, mas sim uma "empresa" pública de prestação de serviços.

No Espírito Santo esse processo vem ocorrendo a partir da implantação de diversas transformações dentre as quais se encontram a criação da Polícia Interativa e a inserção de Programas de Qualidade Total na prestação de serviços à comunidade. Essas mudanças produzem efeitos na vida do policial militar e precisam ser vistas em conjunto com a atual situação sócio-econômica e política do Estado e do País. Antes de tudo, entretanto, é preciso que situemos o policial militar enquanto trabalhador, posto que ele é percebido comumente como uma função institucional, o que torna sua atividade laboral especialmente conflituosa, já que as contradições relativas à função social da corporação militar estão nele incorporadas e através dele personificadas.

\section{Metodologia}

$\mathrm{Na}$ tentativa de detectar os efeitos dessas contradições na saúde do policial e apreender como estes enfrentam as transformações que vêm sendo empreendidas na polícia, realizamos um trabalho de pesquisa/intervenção junto aos trabalhadores de uma das Companhias do $1^{\circ}$ Batalhão da Polícia Militar do Espírito Santo.

Nossa pesquisa teve como objetivo principal compreender os efeitos do trabalho do policial militar na saúde do trabalhador, bem como observar como se dão os processos de subjetivação que são engendrados a partir do seu trabalho. Objetivamos conhecer também como se dá o impacto das mudanças organizacionais e sociais no trabalho da Polícia Militar e como o policial enfrenta essas mudanças. Procuramos perceber, enfim, como os policiais representam a estrutura organizacional da Policia Militar, suas funções e seus efeitos sociais.

Para o presente trabalho utilizamos como base a metodologia da Psicopatologia do Trabalho (Dejours, 1992), sendo respeitadas as particularidades do trabalho da Polícia e as condições nas quais se deram esta pesquisa.

Foram entrevistados ao todo 47 policiais. Sendo quatro oficiais (um tenente-médico, 
dois capitães e um tenente) e 43 praças (sargentos, cabos e soldados). Não foi elaborado um instrumento a priori. Realizamos entrevistas abertas individuais e grupais que se deram a partir de temas gerais (hierarquia, cotidiano e condições do trabalho, jornada de trabalho, características do trabalho do policial, formação do policial, a saúde do trabalhador, a polícia e a mídia), sendo conduzidas a partir dos relatos emitidos pelos próprios policiais.

As entrevistas deram-se a partir de duas reuniões com o capitão da referida Companhia do 1o Batalhão e quatro reuniões com grupos de policiais dessa mesma companhia.

Antes de cada reunião explicitávamos os motivos de estarmos ali, qual nossa concepção de trabalho, e que a participação era voluntária. Os dados foram registrados de forma escrita no momento das entrevistas.

\section{Resultados}

Logo ao iniciarmos a coleta de dados, percebemos que as reclamações dos policiais em relação à corporação da Polícia Militar como um todo apresentavam-se como uma constante nas falas dos trabalhadores. Daí, dentre outros, depreendem-se alguns aspectos: o trabalhador é mal remunerado, com excessiva carga de trabalho, os equipamentos utilizados estão em condições precárias, a hierarquia é considerada abusiva.

Ao aprofundarmos cada um desses aspectos, verificamos que muitos fatores contribuem para que o trabalho do policial militar seja considerado um trabalho bastante controvertido, muito complexo e que envolve intimamente a saúde dos trabalhadores, produzindo subjetividades bastante específicas.

O primeiro aspecto que queremos abordar refere-se à carga de horário do policial. $\mathrm{Na}$ Companhia em que realizamos a pesquisa, a jornada utilizada é de doze horas, sendo intercalada por quarenta e oito horas de "descanso", nas quais se incluem seis horas de escala especial $^{11}$ (ou "horas extras" remuneradas) opcionais que não são contabilizadas na carga horária padrão. Existem também oito horas semanais adicionais, que completam a carga horária prescrita de quarenta horas semanais. Apesar dessa carga horária prescrita, os policiais relatam que trabalham no mínimo quarenta e duas horas semanais, podendo chegar a cinqüenta horas.

Vale ressaltar que, em função do rodízio da escala de horários, há variabilidade de turnos. Ou seja, um policial que trabalha num dia entre os horários das seis às dezoito horas, trabalhará no próximo turno das dezoito às seis horas. Essa escala de turnos variados causa diversos problemas, entre eles a constante variação do ritmo biológico do trabalhador.

O policial perde muita noite de sono e isso descontrola o policial.

Ocorre também que fica dificultada a realização de diversas atividades sociais, como o estudo, o lazer, o encontro com colegas. Ademais, um grande contingente de policiais realizam "bicos" nas suas horas vagas com o intuito de complementação financeira, o que eles citam como um grande causador de males. Alguns chegam mesmo a relatar que a escala, em si, não é problema. O que realmente provoca transtornos é a necessidade de se fazer escalas

\footnotetext{
11 É importante ressaltar que, recentemente, a carga horária da escala especial aumentou para oito horas. O que significa quatro horas semanais a mais.
} 
especiais, horas extras e trabalhos informais nas horas de descanso.

É interessante apontar que, embora exista uma percepção, pelos policiais, dos problemas causados pela carga extra dos "bicos", em uma tentativa recente de se implementar uma escala de 8 horas diárias, encontrou-se, paradoxalmente, uma grande resistência por parte destes. $\mathrm{Na}$ escala de 8 horas diárias restringe-se enormemente a possibilidade de realizações de serviços informais (segurança de festas, boates etc.), o que vai de encontro à grande necessidade de aumento da renda salarial, conseqüente do atraso dos salários pagos pelo Estado.

Finalmente, a escala de doze horas é ainda alargada, já que o policial, no deslocamento casa-trabalho e trabalho-casa, usa a farda e, exatamente por isso, encontra-se na função de policiamento, mesmo estando fora da sua escala de horários. Por exemplo, caso ocorra um assalto num ônibus em que esteja um policial fardado, este é obrigado a dar socorro às vítimas e a tentar resolver o delito, independentemente do fato de ele estar ou não na sua hora de trabalho.

Há, ainda, o fato do policial ser instruído para que, mesmo sem farda, dê apoio às ocorrências que presenciar.

Somos obrigados a assumir.

Tirou a farda ainda é policial.

O policial não pode se omitir mesmo depois do fim da jornada.

Ou seja, onde quer que esteja e em qualquer condição, o policial estará sendo pressionado por uma norma jurídica e institucional que o induz a incorporar a instituição "Polícia Militar" o tempo todo:

A gente veste a camisa da PM o tempo todo.

Além da pressão jurídica e institucional, os policiais são cobrados a agir como tais, durante 24 horas, por toda a sociedade. Eles relataram repetidamente como se dá essa cobrança:

As pessoas cobram que você seja PM o tempo todo.

Mesmo após o fim do trabalho a sociedade vê a gente como policial.

No seu bairro você é referência de todos.

Eles são acionados por seus vizinhos para a resolução de qualquer problema, independente do dia e do horário. Isso é agravado pelo fato de o policial lidar o tempo todo com o que nossa sociedade insiste em esconder, excluir e negar: morte, assassinatos, estupros, brigas, assaltos, miséria, falta de condições básicas de saúde, de vida e de dignidade da população.

Por isso, este sentir-se "policial total" comporta uma grande carga de sofrimento mental, visto que eles carregam consigo, durante todo o tempo, as preocupações, angústias e medos provenientes do trabalho. Um exemplo marcante é o medo de ser reconhecido por pessoas presas por eles e sofrerem retaliações:

A gente sai na praia e não se sente à vontade.

A gente tá o tempo todo observando, vai para o supermercado com a família e fica observando. 


\section{Bandido não fica preso.}

Na medida em que nosso sistema penitenciário e judiciário revela-se incapaz de dar conta da problemática da criminalidade e da "reabilitação" social dos criminosos, os policiais sentem-se alvo preferencial da violência que esses sujeitos dirigem à instituição militar enquanto agente repressor. Mesmo porque, como já salientamos, cada policial carrega em sua farda toda a corporação. Na verdade, quando a usa (ou passa a ter sua identidade associada à vestimenta militar) ele corporifica e materializa essa instituição perante toda a sociedade. É preciso, então, manter-se sempre atento, especialmente por estar fardado grande parte do dia. Pudemos observar que a angústia gerada pela necessidade de estar sempre alerta é fortemente agravada após algum problema.

Depois que o policial passa por uma situação desta [assalto ao banco em que era vigia e o assaltante havia colocado a arma em sua cabeça] ele passa a desconfiar de todo mundo.

Eu só me sinto seguro quando eu ponho o pé dentro de casa; quando eu estou na rua eu fico nervoso o tempo todo.

No entanto, essa posição de policial em tempo integral é marcada por uma forte contradição. Ao mesmo tempo em que esses trabalhadores sentem necessidade de mostrarem-se como iguais aos demais cidadãos,

É difícil a gente sair deste papel, mesmo quando está civil.

Nós também somos seres humanos como vocês.

A gente também é cidadão.

eles acabam por ressaltar sua condição de policial e colocam-se como distintos da sociedade, na medida em que dispõem de certos "poderes" que a maioria da população não possui.

A gente quando é civil, a gente vê algumas coisas de uma maneira, depois vê de outra.

Existe uma mentalidade própria na polícia.

A gente internaliza algumas coisas.

Você consegue detectar algumas coisas.

Nossa técnica de observar é passada na escola, é por isso que nós temos esse dom, essa técnica.

Você é aquele cara policial, superior, é a solução para o problema.

Por meio dessas falas percebemos que os trabalhadores da polícia não abdicam desta diferenciação que os tornam outros que não cidadãos como as demais pessoas. Passam a encarnar o lugar da autoridade, daquele que pode e deve vigiar.

Onde existe mais de duas pessoas e onde existe dinheiro tem problemas e delitos.

Daí ser natural, para eles, o exercício integral e exaustivo da profissão, o qual exige que esses trabalhadores encarnem certos preceitos e formas de ser. Em meio às descrições realizadas acerca do trabalho real observamos a referência constante a uma espécie de "identidade policial". 
Um destes aspectos que surgiu como que caracterizando genericamente esses trabalhadores foi a exigência para consigo:

O policial é muito exigente com ele mesmo.

A frustração de um PM é acontecer um delito e ele não conseguir evitar. É uma derrota sofrer um assalto num lugar que você está policiando.

Na teoria o certo é abordar os sujeitos em maior número, mas na prática isso quase nunca acontece porque para o policial o que importa é resolver a situação.

Nessa última fala vemos que eles conhecem a prescrição da tarefa, porém a desconsideram para poderem realizar bem o serviço policial. Segundo os seus depoimentos, toda essa exigência faz com que eles inevitavelmente passem por momentos em que se sintam impotentes e deprimidos. A isso relacionam problemas de saúde como o estresse, a hipertensão e as cardiopatias que alguns deles apresentam.

\section{Defesas coletivas}

Mesmo considerando explicitamente essas relações entre trabalho e saúde, em suas falas observamos uma certa apologia do "discurso da adrenalina", o qual parece cumprir a função de justificar e valorizar o esforço desmedido, muitas vezes representado pela desconsideração dos riscos que o trabalho em certas situações impõe à sua vida:

Tem os problemas materiais que atrapalham tudo, mas na hora da ocorrência a gente nem pensa nisso.

Quando a gente ouve pelo rádio que tem um assalto em andamento a adrenalina sobe muito.

Às vezes a gente entra num matagal, troca tiro com os meliantes e depois é que percebe que se um tiro daqueles tivesse pegado o seu destino, que é a gente, tinha tudo acabado. Mas na hora a gente nem pára para pensar que não vale a pena morrer por causa de marginal...

Nesse sentido ser policial é, para eles, algo que corre nas veias, um impulso, uma vocação; muito embora eles próprios digam que isso apenas surge depois que ingressam na corporação. Podemos apreender esse discurso como uma verdadeira "ideologia ocupacional defensiva"(Dejours, 1992, p. 69), na medida em que atenua o medo e a ansiedade decorrente da percepção do risco inerente ao trabalho policial, o qual é muitas vezes exacerbado pela falta de condições materiais apropriadas (coletes, armas, carros adequados, balas). Esta hipótese consolida-se quando observamos que este discurso permeia a fala de grande parte dos trabalhadores que vivem o cotidiano da rua, os quais estão mais expostos a esse tipo de ocorrência. Considerando todos esses aspectos é possível dizer que esta defesa assegura a execução do trabalho, minimizando a relação destes trabalhadores com essas contradições e seus aspectos paralisantes.

Concomitante ao "discurso da adrenalina", aparece o "discurso da naturalização da morte" servindo como mais uma defesa coletiva. Para os policiais, "O risco se torna uma rotina, matar ou morrer é algo natural". Consideram mesmo que dentre as funções da polícia destaca-se o "matar e o morrer":

Nós temos mil funções na rua, não só a de prender, de matar, de morrer.

Apesar de apontarem bastante para a questão da vocação, os policiais dizem que, na maioria dos casos, a procura pelo serviço policial dá-se em função da necessidade financeira, da estabilidade da profissão e da dificuldade em encontrar outros empregos: 
Há 19 anos eu entrei na polícia pelo mesmo motivo que ele [colega ao lado] entrou há três.

Quem entra na polícia? Quem fez escola pública, quem não teve oportunidade. classe média não vira soldado.

A dita vocação pode ser então analisada como um dos fatores que apara o "discurso da adrenalina" e que forja uma certa identidade policial, que surge, segundo eles, apenas com o decorrer do exercício profissional

A vocação vem com o tempo.

Mesmo porque foi bastante acentuado por eles o fato de que a formação que os prepara para o trabalho é bastante deficitária, embora venha melhorando nos últimos anos. Apesar de reconhecerem tal aperfeiçoamento, ainda hoje concebem o trabalho como algo que se aprende "de verdade" em sua execução concreta; ou seja, na rua:

A gente aprende mesmo é na rua.

Tem uma instrução por ano, mais é muito rápida e muito vaga.

O dia-a-dia é a melhor aula.

O que a gente aprende é pela experiência.

A formação do policial é péssima.

O treinamento não mudou: hoje tem Psicologia, tem Sociologia, mas a gente ainda é preparado para a guerra, e depois vai para a rua prá fazer trabalho assistencial.

\section{Hierarquia}

Esta última fala nos remete a um dos traços mais marcantes desta instituição: o militarismo. A importância de abordá-lo deve-se ao fato de, ainda hoje, toda a corporação militar estruturar-se em função dessa filosofia, e foi direcionada a essa organização militarista de trabalho que surgiram as mais enfáticas críticas por parte dos trabalhadores. Cabe esclarecer que nos referimos essencialmente nesse ponto à questão da hierarquia.

O tema da hierarquia surgiu acompanhado de muita comoção por parte dos policiais. Em seus relatos e queixas, eles acentuavam prioritariamente o caráter abusivo, arbitrário e humilhante por meio do qual a superioridade hierárquica é exercida pelos oficiais ${ }^{12}$ :

Os comandantes pedem que o soldado seja cortês com o cidadão, mas dentro da corporação eles são abusivos e autoritários.

Sabe como eles tratavam a gente na época da ditadura: "vocês são ovo de porco, são o resto do cocô do cavalo do bandido que não entrou em cena".

Falavam que a gente não tinha direito e que não podia abusar do direito que a gente não tinha.

\footnotetext{
12 Temos que esclarecer que não nos preocupamos em averiguar a veracidade destes relatos, uma vez que o que importa para o cunho teórico que direciona nossa análise é a forma como o trabalhador percebe e sente a organização de seu trabalho.
} 
Se depender dos oficiais, coitado da gente. Agora tá melhorando um pouco por causa da polícia interativa.

Eu não contava com a hierarquia que existe, como era difícil conviver com essa submissão da hierarquia.

Esta característica do trabalho policial foi-nos apresentada como uma das maiores responsáveis pelo desgaste associado a essa profissão, sendo indicada como uma intensa fonte de sofrimento psíquico. Este sofrimento, sempre presente no trabalho, decorreria da rígida estrutura organizacional da instituição militar, na qual o soldado representa o lugar principal da desqualificação. Este lugar é claramente demarcado dentro da corporação através da instituição precisa e formal da divisão entre trabalho intelectual (função dos oficiais, que consiste no planejamento estratégico das ações e dos cursos de formação) e trabalho físico (função dos praças, que se dá nas ruas).

Essa diferenciação produz um conflito permanente entre esses postos hierárquicos, que se traduz em assertivas como estas:

Ninguém vê oficial na rua trabalhando.

Eles [os oficiais] têm horário certinho, de oito às seis, e ficam o tempo todo atrás de uma mesa dando os comandos.

Paradoxalmente, alguns deles referem-se a uma certa igualdade de pressão em todo trabalho da polícia:

Pode mudar de cargo mas a dor de cabeça é igual dentro da polícia.

O conflito engendrado por essa configuração específica do trabalho policial torna-se ainda mais complicado para os praças, na medida em que eles se sentem não apenas marginalizados na e pela hierarquia, mas também pela sociedade que devem proteger e pela qual devem zelar.

Foram relatados diversos casos em que os policiais, atuando no próprio cumprimento de seu dever, contrariaram direta ou indiretamente os interesses de seus superiores, sofrendo retaliações, apesar de estarem respeitando a lei.

Ao perguntarmos se eles não tinham como se defender deste tipo de perseguição, relataram que não, pois, em função do corporativismo, um oficial dificilmente contraria a ordem de um outro. Além disso, a rígida estrutura militar impede quaisquer formas de organização coletiva que possam proteger estes praças enquanto categoria dentro da organização do trabalho. Eles não podem sindicalizar-se, nem mesmo fazer greve, pois ambas as coisas são expressamente proibidas pelas normas internas da corporação. São consideradas como insubordinação e motim e, nessa medida, passíveis de severas punições.

Quando perguntamos como faziam para trabalhar em meio a essas dificuldades, eles afirmaram evitar a todo custo contrariar seus superiores, mesmo que isso significasse desrespeitar a lei. Os policiais disseram ainda que evitam ao máximo levar problemas e obstruir o trabalho dos oficiais, uma vez que têm medo das retaliações dentro da própria corporação. Isso porque, como dissemos, não existem meios legais que os protejam contra elas.

Macaco velho não mete a mão em cumbuca.

Ainda quanto às dificuldades trazidas pela estrutura e pela organização da polícia militar, os soldados trouxeram para o debate o problema das punições utilizadas para os casos 
de desvio da norma. Segundo eles, elas são extremamente desproporcionais e abusivas.

Eles relataram que muitas vezes são presos para averiguação assim que é feita qualquer denúncia ou queixa. Nessa situação podem permanecer presos meses (às vezes seis, sete ou mais) sem que seja preciso nenhuma comprovação do motivo em questão, ou seja, sem que haja qualquer fato que prove sua implicação. São culpados até que se prove o contrário. Segundo eles, existem casos em que policiais foram presos por causa de depoimentos em que as testemunhas identificavam "a barriga do policial" ou "bico do seu revólver".

Um dos soldados expressou de modo claro toda a carga de conflito e sofrimento psíquico acarretada por esses contextos. Fez isso ao perguntar-nos como achávamos que fica um policial numa situação em que se encontra preso por meses, mesmo sabendo-se inocente. Perguntou-nos, ainda, como fica o soldado perante o fato de ter que permanecer todo esse tempo enjaulado como se fosse o bandido; longe de sua família, que muitas vezes ele próprio não quer que o visite para que não se veja na situação de ter que responder a um de seus filhos porque ele está preso se é policial.

É interessante ressaltarmos que grande parte das vezes os policiais não dirigiam seus protestos à estruturação hierárquica da instituição. Ao contrário, reconheciam sua importância enquanto fator fundamental à organização do trabalho. O que parece incomodálos é o fato de serem eles os mandados e humilhados, segundo suas próprias palavras. Tanto que, quando perguntávamos o que os estimula a ascender na corporação, eram consensuais as seguintes respostas: queriam fazê-lo por causa do aumento salarial, mas também para poderem mandar e comandar.

Nesse sentido constatamos que a quase impossibilidade de um praça ascender à condição de oficial dentro da própria corporação, seja por tempo de serviço ou por trabalhos e concursos prestados, é um elemento bastante frustrante do trabalho, especialmente para os soldados mais jovens e com menos "tempo de casa".

O trabalho dos policiais militares trazem ainda características próprias que acentuam o seu esforço cognitivo sobremaneira. A variabilidade das ocorrências é um fato registrado nas entrevistas:

Você pode atender mil ocorrências, mas sempre uma é diferente da outra.

Cabe a eles decidirem o que fazer e como fazer a cada momento. Esta "tomada de decisão" é exigida o tempo todo: detectar suspeitos em meio a uma multidão; premeditar situações anormais; o que fazer numa ocorrência; qual a estratégia a ser adotada numa ação imediata ou ainda como agir com o pouco material que dispõem.

O policial olha para ver alguma coisa de anormal...

...numa ocorrência a gente é um juiz, a gente tem que tomar a decisão na hora, que pode ser equivocada...

Quando o rádio chama a gente para um assalto a banco a gente vai pensando o que vai fazer no caminho, mas quando o assalto é muito perto a gente resolve na hora...

Isso se mostra ainda mais evidente porque atualmente (setembro de 1998) o governo do Estado parou de repassar as verbas para a corporação, e os policiais vêem-se obrigados a improvisar para suprir as suas necessidades materiais: consertar as viaturas porque são velhas e quebram muito, compra de balas (os colegas da companhia juntam-se para adquirir a munição), alguns chegam mesmo a colocar combustível nas viaturas para poder andar com maior autonomia. O que seriam obrigações do Estado são supridas por iniciativas individuais 
e grupais.

As mudanças não acontecem por causa da corporação, mas por causa da vontade das pessoas.

Essa exigência traz a tona algumas realidades que demonstram o nível de cobrança que esses trabalhadores sofrem cotidianamente. Isto porque, ao mesmo tempo que os policiais têm que tomar diversas decisões, não lhes é dado o direito de errar. $\mathrm{O}$ sentimento de perseguição por parte da imprensa, a exigência dos outros níveis hierárquicos e seu próprio orgulho de "policial total" fazem-nos conviver com a constante ansiedade do "não errar". Tudo isso vem colaborar com o agravamento do sofrimento mental desses trabalhadores.

\section{Contradições da função, contradições da identidade. Riscos psíquicos?}

A Polícia Militar tem seu papel bem definido: "manter a ordem pública, prevenindo sempre antes de reprimir". Entretanto, as relações cotidianas do trabalho parecem não seguir esta premissa. Tanto a sociedade quanto a corporação exigem idealmente que os policiais mantenham uma determinada postura frente ao social, sendo que esta postura é freqüentemente diversa daquilo que é exigido aos trabalhadores da polícia - exige-se que sejam policiais que respeitem os direitos do cidadão e utilizem a repressão apenas em último caso. No entanto, a força policial é utilizada diversas vezes de modo estrategicamente repressor, atendendo aos interesses do capital na manutenção das estratificação social. E isso é apenas mais umas das contradições da função da PM. Contradições percebidas pelos policiais e certamente perturbadoras:

Como eles vão educar a gente para atender o cidadão, se eles precisam da gente reprimindo?

Embora percebam-se como "testas de ferro" - "somos [os policiais] usados como testa de ferro" -, mantendo uma ordem pré-estabelecida pelos interesses de um grupo ou de uma classe, ainda assim, os valores e normas da polícia são internalizadas através da hierarquia, de forma a agirem prontamente a qualquer comando de ação.

Segundo os policiais, alguns oficiais supõem que as estratégias da polícia são executadas por máquinas (de guerra) não pensantes, nos moldes do operário taylorista, mas certamente a natureza da ação á analisada pelos policiais através de seus filtros de valor e suas bagagens históricas. Então, além de representarem a polícia como necessária, passam também a apreendê-la como "cachorro do governo". E poderíamos representar a "função" da polícia de outra maneira que não essa, já que são ativados para contextos tão delicados socialmente?

Estes são exemplificados pelos trabalhadores através de situações que vivenciam, chamando a atenção para a dificuldade de se lidar emocionalmente com essas situações:

Certo dia um policial fora chamado para efetuar uma ocorrência de roubo. Era uma mulher que, grávida, havia roubado uma certa quantidade de arroz do hotel em que trabalhava. Após efetuar a prisão em flagrante da mulher, o dono jogou fora todo o arroz roubado na presença do policial. Isso o indignou profundamente.

Um outro caso citado foi de uma repressão a um movimento reivindicatório de um grupo de trabalhadores. Estando também na situação de trabalhador, com meses de salário atrasado como eles, os policiais tinham que reprimir uma manifestação que consideravam legítima.

Essa contradição acentua-se quando, diante de tal postura político-social, o policial começa a ser massacrado pela mídia e enquadrado por esta em uma imagem negativa de violência e abuso de poder. 
Através dos relatos dos trabalhadores pudemos evidenciar aspectos no que diz respeito à mídia e à produção de estereótipos. Como já foi dito anteriormente, há socialmente um estereótipo negativo quanto ao policial e a instituição polícia militar. Segundo os entrevistados, tal imagem é constantemente produzida e reafirmada pela mídia:

Somos alvo fácil da imprensa.

Se fizermos mil coisas boas não iremos aparecer, mas se fizermos a primeira besteira, está no jornal do outro dia.

Como podemos ver, há uma enorme queixa dos trabalhadores em relação a esse órgão do sistema - a imprensa - que afinal de contas é um produtor de cultura, opinião e, acima de tudo, realidades. Essas "besteiras" a que se referem os trabalhadores também são frutos de uma maior liberdade de decisão do que fazer, que muitas vezes partem de uma ordem pessoal "equivocada", dando margem a manipulações maiores e apelativas que são aproveitadas pelos meios de comunicação no intuito de criar polêmica e aumentar as vendas.

Por outro lado, sustenta-se socialmente um estereótipo positivo dos policiais, que os identifica a Robocops, verdadeiras máquinas que trabalham incessantemente em prol da segurança pública. Esse é um outro ponto de sofrimento psíquico dos trabalhadores, já que eles tentam corresponder a tal estereótipo:

Você fica frustrado por terem assaltado o local que está cuidando.

Você perde a auto-estima.

É sabido que a segurança pública não é responsabilidade apenas do policial e sim de todo um sistema. No entanto, como o policiamento ostensivo é o que mais aparece nesse processo, o que entra em contato direto com a população, é no policial que recai a frustração individual bem como a da sociedade.

Tentamos não transmitir a frustração e o sentimento de derrota para o público.

Todavia existe um outro agravante: as contradições sociais e históricas na nossa sociedade. A pergunta feita pelos policiais apresenta-se pertinente:

Que interesse tem a sociedade de ter uma polícia estruturada e bem paga?

Frente a toda essa lógica social repressiva, alguns grupos sociais aproveitam-se da polícia atuando dessa forma em benefício próprio: para os policiais, entre esses grupos destacam-se os "ricos" e o "judiciário":

Errar com uma pessoa de São Pedro [bairro pobre de Vitória, ES] é diferente de errar com alguém da Praia do Canto [bairro nobre de Vitória, ES]

Você pode estar trabalhando certo, mas se mexer com gente grande você está frito.

Principalmente se essa "gente grande" for alguém do judiciário ou familiares desse: advogado, juiz, desembargador etc. Contam-se muitos casos em que, após efetuarem ocorrências com pessoas desse meio, os policiais é que são os punidos. Casos que indignam os policiais que se perguntam:

...mas e agora, como fazer? Se eu vou e prendo a pessoa eu é que pego cadeia e fico com a minha ficha suja; se eu não prendo, os moradores reclamam do meu serviço.

Fica-se portanto num impasse constante: 
Se você toma a providência certa, você é punido porque fez, se você não fizer, é punido na polícia por não fazer.

\section{Conclusões}

Diante destes dados observamos que o trabalho policial caracteriza-se principalmente pela extensão da atividade profissional a todos os âmbitos da vida do trabalhador (policial 24 horas por dia) e pela vivência concreta e cotidiana das contradições sociais, próprias das lutas de classes. Vivem o contra-senso de serem cobrados por aplicarem uma lei que não é lei para todos.

Essas peculiaridades atravessam-nos não apenas como uma determinada identificação institucional, mas como uma constante no seu cotidiano, ocasionando um grande sofrimento mental.

O impasse de não poder fazer aquilo que socialmente se exige que o policial faça acaba por levá-lo a um nível de tensão que merece consideração. Por outro lado, situações como essas acabam por possibilitar aos trabalhadores lançar mão da sua criatividade e de sua inteligência. Cria-se, portanto, um campo de ação em que o policial terá que lançar mão de diversos recursos para tentar "agradar a todos".

Enfim, como agir com tantas contradições? E qual será o preço psíquico ao se reprimir o pobre que rouba para comer, ao se reprimir o trabalhador que luta por seus direitos, ao ser reprimido por executar corretamente o seu serviço, ao executar uma função exigida socialmente e ser criticado por ela? E como trabalhar em seu próximo turno, como se nada houvesse acontecido, após experimentar tais situações? E o que fazer se não é possível deixar em casa seu "pensamentos e valores" quando está a realizar a sua função de polícia? Qual é o peso de uma "pressão moral" como essa se o policial é policial 24 horas por dia? Quais são, portanto, as origens dessas contradições? Contradições na função da polícia? Contradições da função no policial? Contradições do policial na função? As contradições da nossa sociedade.

Os fatores de sofrimento psíquicos presentes na labuta do policial são agravados pela ausência de espaços para sua análise coletiva na instituição militar. Isto foi demonstrado através de uma demanda explícita dos trabalhadores. A criação de espaços para fala é de nodal importância num ambiente em que os dizeres e as vontades têm que fazer continência.

A premissa de que a polícia existe para servir a população é "ensinada" numa instituição de ações hierarquizadas, autoritárias e abusivas, onde o trabalhador policial é também desrespeitado, inclusive, no exercício de sua atividade. Essa é uma questão para o policial e para o não-policial, todos nós atores da construção social diária.

From "elemento" to citizen ${ }^{13}$ : transformations in the everyday work life of the policeman.

The Military Police of Espirito Santo has been going through transformations among which are found the creation of the Interactive Police and the inclusion of Total Quality Programs in the

\footnotetext{
13 The technical term elemento, solely used in Brazilian police argot with this meaning, refers to any common person and, much like the scientific term subject, lacks the socio-political connotation borne by the term cidadão (citizen).
} 
performance of services to the community. These changes produce effects on the life of the Military Police worker and need to be seen jointly with the current socio-economical and political situation of the Nation and of the State. In an attempt to grasp the effects of these transformations in the policeman's health, we have carried out a research/intervention program with workers of a given company of the 1st Batallion of the Military Police of Espirito Santo. From the obtained data we have been able to notice that police work is characterized by the extension of the work activity to all the scopes of the worker's life, moving through it not only with a given institutional identification, but also with the conflicts and contradictions which distinguish the function of these workers, causing great mental suffering; mental suffering such that is worsened by the lack of spaces for its collective analysis in the military institution.

Keywords: social psychology, military police, worker's health.

Endereço para contato com os autores: Maristela Dalbello Araújo, Departamento de Psicologia da Universidade Federal do Espírito Santo Av. Fernando Ferrari, s/n, Goiabeiras, Vitória, Espírito Santo, 29060-900. Endereço eletrônico: dalbello@npd.ufes.br

Manuscrito recebido em: 25/09/1999 Aprovado para publicação em: 27/10/1999

\section{Referências bibliográficas}

Barbosa, R. L. M. et al. (1998). O perfil sócio-cultural do soldado da polícia militar. Vitória. [digitado]

Cardia, N. (1997). O medo da polícia e as graves violações dos direitos humanos. Tempo Social, 9 (1), 249-265.

Dejours, C. (1992). A loucura do trabalho: estudo de psicopatologia do trabalho. São Paulo: Cortez-Oboré.

Paixão, A. L. \& Beato, F. (1997). Crimes, vítimas e policiais. Tempo Social, 9 (1), 233-248.

Tavares dos Santos, J. V. (1997). A arma e a flor: formação da organização policial, consenso violência. Tempo Social, 9 (1), 155-167. 